\title{
What maximizes the effectiveness and implementation of technology-based interventions to support healthcare professional practice? A systematic literature review
}

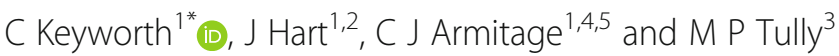

\begin{abstract}
Background: Technological support may be crucial in optimizing healthcare professional practice and improving patient outcomes. A focus on electronic health records has left other technological supports relatively neglected. Additionally, there has been no comparison between different types of technology-based interventions, and the importance of delivery setting on the implementation of technology-based interventions to change professional practice. Consequently, there is a need to synthesise and examine intervention characteristics using a methodology suited to identifying important features of effective interventions, and the barriers and facilitators to implementation. Three aims were addressed: to identify interventions with a technological component that are successful at changing professional practice, to determine if and how such interventions are theory-based, and to examine barriers and facilitators to successful implementation.
\end{abstract}

Methods: A literature review informed by realist review methods was conducted involving a systematic search of studies reporting either: (1) behavior change interventions that included technology to support professional practice change; or (2) barriers and facilitators to implementation of technological interventions. Extracted data was quantitative and qualitative, and included setting, target professionals, and use of Behaviour Change Techniques (BCTs). The primary outcome was a change in professional practice. A thematic analysis was conducted on studies reporting barriers and facilitators of implementation.

Results: Sixty-nine studies met the inclusion criteria; 48 (27 randomized controlled trials) reported behavior change interventions and 21 reported practicalities of implementation. The most successful technological intervention was decision support providing healthcare professionals with knowledge and/or person-specific information to assist with patient management. Successful technologies were more likely to operationalise BCTs, particularly "instruction on how to perform the behavior". Facilitators of implementation included aligning studies with organisational initiatives, ensuring senior peer endorsement, and integration into clinical workload. Barriers included organisational challenges, and design, content and technical issues of technology-based interventions.

(Continued on next page)

\footnotetext{
* Correspondence: chris.keyworth@manchester.ac.uk

${ }^{1}$ Manchester Centre for Health Psychology, Division of Psychology and

Mental Health, School of Health Sciences, Faculty of Biology, Medicine and

Health, University of Manchester, Manchester Academic Health Science

Centre, Coupland 1 Building, Oxford Road, Manchester M13 9PL, UK

Full list of author information is available at the end of the article
}

(c) The Author(s). 2018 Open Access This article is distributed under the terms of the Creative Commons Attribution 4.0 International License (http://creativecommons.org/licenses/by/4.0/), which permits unrestricted use, distribution, and reproduction in any medium, provided you give appropriate credit to the original author(s) and the source, provide a link to the Creative Commons license, and indicate if changes were made. The Creative Commons Public Domain Dedication waiver (http://creativecommons.org/publicdomain/zero/1.0/) applies to the data made available in this article, unless otherwise stated. 
(Continued from previous page)

Conclusions: Technological interventions must focus on providing decision support for clinical practice using recognized behavior change techniques. Interventions must consider organizational context, clinical workload, and have clearly defined benefits for improving practice and patient outcomes.

Keywords: Healthcare professional behaviour change, Technology, Realist review, Intervention, eHealth

\section{Background}

Changing healthcare professional practice is fundamental to the implementation of any health policy, intervention or safety measure intended to deliver best patient care. This is particularly important given the responsibilities that healthcare professionals have with respect to patient management and improving health outcomes [1]. Previously targeted behaviors include prescribing medication [2], conducting screening and health checks [3, 4], providing support and making appropriate referrals [5], and making diagnoses [6]. Optimizing performance of these target behaviors provides an opportunity to influence directly the clinical management of patients and hence accelerate improvement in patient care and/or patient outcomes.

Technology-based interventions can address known barriers in the work environment such as time and workload pressure [7] and provide an opportunity to exert greater impact on patient outcomes by changing professional practice rather than changing the behavior of patients one-by-one. Interventions with a technological component include automated prompts and reminders to support clinical management of patients [8], computer-based skills training [9], and IT-based healthcare professional decision support for clinical decision making [10].

Previous reviews have examined the use of technologies to support healthcare professional practice, such as email to support clinical communication between professionals [11], electronic health information to improve clinical practice (professional behaviors or adherence to clinical practice guidelines) [12], on-screen reminders (such as prompts to conduct a clinical test), and computer-generated reminders delivered on paper [13]. The majority of the preceding literature has tended to focus on effectiveness only, and includes specific interventions, within specific settings, such as electronic health records [14] and computerised provider order entry [15] only. This limits the generalisability of findings to other settings in relation to developing interventions to be delivered at scale.

In addition, it is widely recognized that interventions are most effective when based on behavior change theory and techniques $[16,17]$. The use of theory is necessary for explaining and identifying target beliefs involved in clinical practice, and offers a framework for designing and conducting interventions [18, 19]. An important omission from previous reviews is whether technology-based interventions aimed at healthcare professional behaviour change include recognised behaviour change techniques (BCTs), and an understanding of whether such interventions are more or less effective with the inclusion of BCTs. Consequently, there is a need to examine whether interventions with a technological component aimed at changing healthcare professional practice include recognized $\mathrm{BCTs}$, and whether those interventions including $\mathrm{BCT}$ s are more effective than interventions without.

There are examples of reviews that focus on implementation of e-health interventions within healthcare settings generally; Ross et al. provide a series of recommendations for implementing e-health interventions across a range of settings [20], however measures of behaviour are not included. Consequently, to build on the previous literature, there is a need to consider the importance of changing healthcare professional practice alongside understanding issues in relation to the implementation of technological interventions. Simply providing healthcare professionals with new technology is unlikely to lead to the transformation in health care that such new technology is proposed to deliver. Specifically, there is a need to conduct an overarching synthesis of diverse technology-based interventions that aim to change healthcare professional behaviour which focuses on three key areas: (1) identifying specific features associated with intervention effectiveness (i.e. what works, for whom interventions for, and under what circumstances interventions work), (2) the BCTs associated with successful interventions, and (3) the barriers and facilitators associated with successful implementation of technology-based interventions. Consequently, there is a need to synthesise and examine intervention characteristics using a methodology suited to identifying important features of effective interventions, and the barriers and facilitators to implementation.

Traditional systematic reviews focus on effectiveness of interventions only. Realist review methods, on the other hand, provide a means of evidence synthesis focused on providing explanations for how and why interventions may or may not work, and aims to identify features of successful interventions [21]. The advantage of using realist methods over more traditional systematic review methods, is the ability to search for specific explanations regarding implementation of interventions, with no limitations on study design [22-26]. Intervention 
characteristics (such as study setting, population, and intervention category), as well as the barriers and facilitators of implementation, can be examined using realist review methods to provide a detailed picture of intervention characteristics above and beyond traditional review methods. A realist approach is particularly suited to synthesising evidence about complex interventions [21, 27], including technology-based interventions [28]. This approach determines which interventions work (e.g. computer-based training versus automated reminders), for whom they work (e.g. general practitioners versus nurses), and under what circumstances (e.g. study setting such as primary versus secondary care) they are most effective $[29,30]$. This provides rich, detailed and a highly practical understanding of interventions, which is particularly important when planning and implementing interventions on a wider scale [30].

Three specific research questions were addressed:

1. What are the key features of interventions with a technological component that are successful at changing healthcare professional practice?

2. If and how do such interventions include Behaviour Change Techniques (BCTs) [17] and does the inclusion of $\mathrm{BCTs}$ make a difference to practice change?

3. What are the barriers and facilitators to successful implementation of technology-based interventions in practice?

\section{Methods}

A literature review informed by realist review methods was conducted using the five-stage approach [21]: (1) establishing the focus of the review; (2) using a purposive and theoretically driven search strategy and appraisal of literature; (3) searching for multiple types of evidence; (4) using an iterative process throughout; and (5) ensuring the findings explain why (or why not) interventions work and how they work, and provide suggestions for future research and practical application of successful interventions.

\section{Inclusion criteria}

There were no limitations on study design. Interventions targeting any healthcare profession were included. Technology was defined as any aspect of an intervention that involves information technology used as part of patient management strategies (such as computer-generated reminders or alerts).

Studies must have reported: (a) interventions with at least one healthcare professional outcome relating to a change in behavior/practice. For example, changes in professional behavior, action or performance (such as appropriate prescribing or adherence to clinical guidelines); or (b) the practicalities of delivering such interventions using technological supports.

\section{Search strategy}

Systematic searches were conducted in the following electronic databases (up to December 2016): Medline, Embase, Cumulative Index to Nursing and Allied Health Literature (CINAHL), PsycINFO, ISI Web of Science, and Cochrane Library. The reference lists of key systematic review papers were also included in the hand search of all relevant papers. Conference abstracts/reports identified through the database search were only included if they provided sufficient outcome data relating to changes in healthcare professional practice.

A broad search strategy (Additional file 1) was used to capture the widest possible numbers of studies from a range of categories, which included both intervention studies and studies reporting the practicalities of delivering interventions. Medical Subject Headings (MeSH) terms and key words relating to healthcare professional behavior change and technological supports were used.

\section{Screening}

After the initial literature search, two authors (CK and MPT) screened titles and abstracts according to the inclusion criteria. Where abstracts provided insufficient information, full-text review was carried out. Papers meeting the final inclusion criteria were then categorised into two groups; those reporting the results of behavior change interventions aimed at healthcare professionals, and those reporting the practicalities (barriers and facilitators) of delivering such interventions (Additional file 2).

\section{Data extraction and analysis}

Data analysis focused on three phases: (1) a quantitative descriptive analysis to identify and evaluate the characteristics of interventions, (2) coding interventions for recognized behavior change techniques (BCTs), and (3) a thematic analysis of the practicalities of designing and implementing technological interventions.

\section{(1) Characteristics of interventions}

Key study characteristics were tabulated using an Excel spreadsheet (including study year, country and healthcare setting). Particular emphasis was given to principles consistent with realist review methodology: the type of intervention used, at whom the intervention was targeted, and the circumstances under which the intervention was described as being effective (target behavior and setting). Specific elements of the intervention were categorised to provide explanations of their effectiveness (a positive change in healthcare professional practice, 
where $p<.05$, or ineffectiveness, to determine which interventions work) [21]. Study effect sizes were calculated where possible. This included contacting study authors to obtain any missing information. The primary outcome was whether the intervention resulted in a change to healthcare professional clinical practice (both objective and self-reported).

\section{(2) Coding interventions for BCTs}

A coding frame was informed by a recognized taxonomy of BCTs [17]. Whilst analysis of behavior change interventions aimed at healthcare professionals has not previously been conducted in the context of technological supports, coding of a similar nature has been conducted in other contexts [31].

Coding was conducted by authors with previous experience of using the BCT taxonomy. One of the study authors (CK) coded the interventions for evidence of BCTs according to the standardised definitions [17], and included both implicit and explicit use of BCTs. A second coder $(\mathrm{JH})$ independently screened a sample selected at random. Disagreements were resolved after discussion, and a third coder (MT) was consulted if agreement could not be reached. An Excel spreadsheet was used to create the coding frame and record intervention descriptions and frequencies of BCTs.

(3) Thematic analysis of the practicalities of designing and implementing technological interventions.

The qualitative software data management tool NVivo was used to sort and categorise the data. Analysis involved coding each study in terms of capturing key ideas and understandings and linking this with the emerging theoretical framework [32]. Thematic analysis was used to provide the best approach to evidence synthesis according to the pre-defined research questions. Findings were summarised under key thematic headings, according to the main findings of each paper, which were used to inform the overall description of the key points [33]. Codes from all identified studies were then compared and cross-referenced, and organised into recurring/higher order themes.

\section{Results}

A total of 69 papers were included in the final analysis; 48 studies (of which 27 were randomized controlled trials) were identified in which there was a technological component used to support healthcare professional practice change, and 21 papers reported the practicalities associated with the design and implementation of technology-based interventions (Fig. 1). One paper [34] was included in both parts of the analysis.

\section{Characteristics of interventions}

Forty-eight studies (Table 1) met the inclusion criteria to answer review questions 1 (features of effective behavior change interventions with a technological component), and 2 (if and how behavior change theory was used in the interventions). These were conducted in the USA $(n=25)$, United Kingdom $(n=7)$, The Netherlands $(n=4)$, Australia $(n=4)$ or elsewhere $(n=8)$. One study did not report the country in which the study was conducted.

\section{Types of intervention}

Results are presented in Table 2. The use of healthcare professional decision supports, defined as a decision support system providing healthcare professionals with knowledge and/or person-specific information to assist with patient management [35], was the most commonly used technological intervention ( $n=19$ studies); 15 of the 19 (79\%) interventions were effective. We were able to extract effect sizes for 12 studies relating to 29 outcomes (small; $n=19$, medium; $\mathrm{n}=; 3$, large; $n=7$ ) according to definitions provided by Cohen [36].

The second most commonly used intervention group was reminders and alerts ( $n=11$ studies), and this also had the second highest percentage of effective interventions (7 of 11 effective; 64\%). We were able to extract effect sizes for 3 studies relating to 4 outcomes (small; $n=2$, medium; $n=1$, large; $n=1$ ).

There were several groups of less frequently used interventions, but that were shown to be effective. One study examined computer-generated feedback, showing positive effects. We were able to extract effect sizes relating to three outcomes (small; $n=3$ ). Relating to use of email, 3 of 3 studies showed positive effects. Effect size was calculated for one study relating to one outcome (large; $n=1$ ). In the category electronic feedback system, one study showed positive effects, with an effect size relating to six outcomes (small; $\mathrm{n}=1$, medium; $n=4$, large; $n=1$ ).

Due to the heterogeneity of the studies it was not appropriate to compute summary statistics. In addition due to the varied reporting of study results, we were only able to calculate effect sizes for a sub-sample of papers $(n=27)$, of which there was considerable variation in the size of the effect of reported outcomes (small; $n=$ 31, medium; $n=10$, large; $n=12$ ). A forest plot illustrating the range of effect sizes for each outcome of interest is presented in Additional file 3.

\section{Setting of intervention}

Whilst the most common intervention setting for technological interventions was primary care $(n=23$; $48 \%)$, studies conducted in hospitals $(n=14 ; 28 \%)$ had a higher success rate (12 of 14 described as effective; $86 \%$ ). Other less frequent settings included interventions 


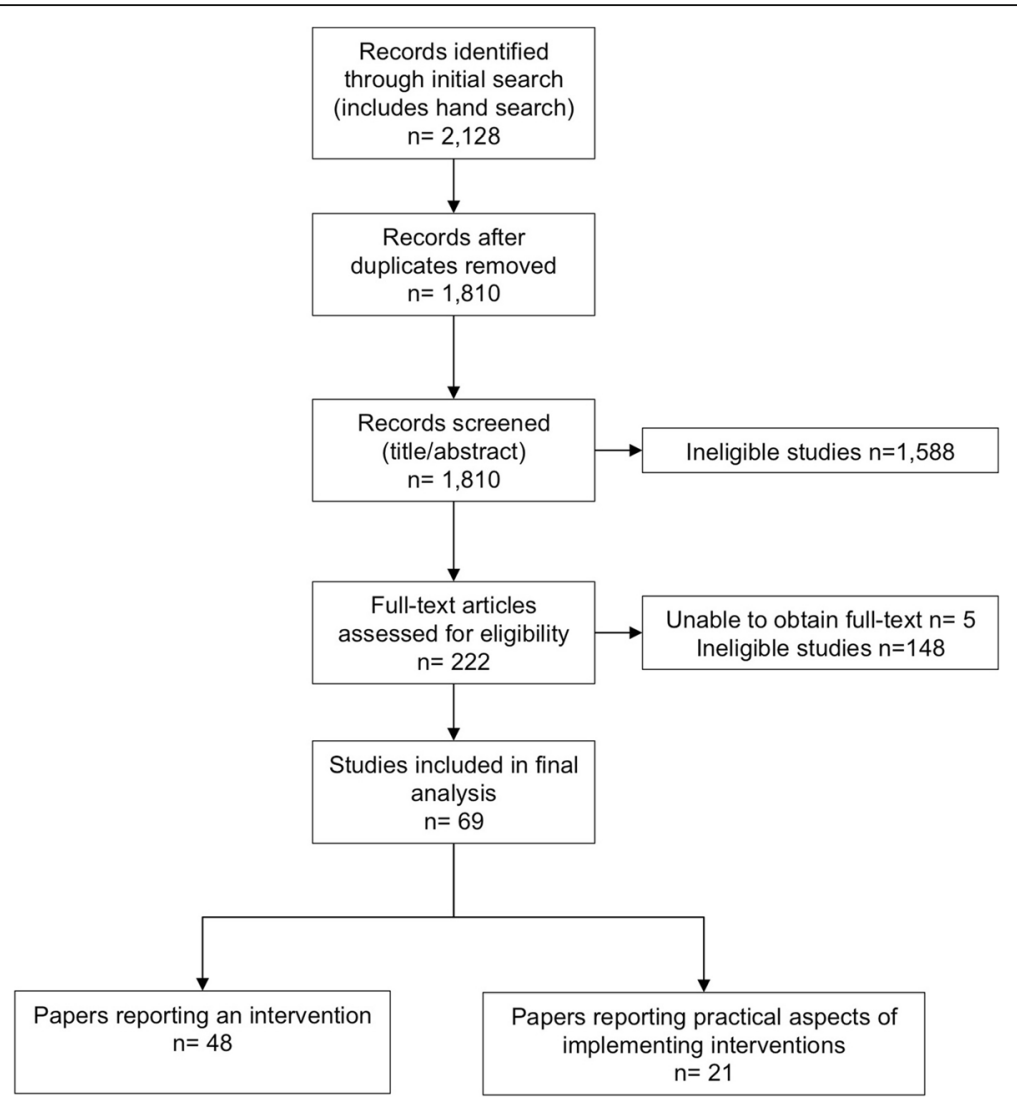

Fig. 1 Flow diagram of search strategy

conducted within both primary and secondary care (1 of 2 effective; $50 \%$ ).

\section{Target healthcare professional for intervention}

Half of the interventions were targeted at General Practitioners $(n=24 ; 50 \%)$, with this group also having the highest success rate (18 of 24 studies [75\%] resulting in professional behavior change). The second largest group were interventions targeted at two or more types of healthcare professional $(n=16 ; 33 \%)$, over half of which resulted in practice change (10 of $19 ; 61 \%)$. There were several other groups of less frequently targeted healthcare professionals among whom technology-based interventions had been tested. These included interventions targeted at mental health therapists ( 2 of 2 effective; $100 \%$ ) and pharmacists (1 of 2 effective; $50 \%$ ).

\section{Target behavior of intervention}

Interventions according to target behavior are presented in Table 2. The most common behavior targeted by technological interventions was adherence to clinical guidelines for patient management $(n=17 ; 35 \%)$, over half of which were effective in changing practice (10 of 17 studies; 61\%).
The second most commonly targeted behavior was prescribing behaviors $(n=15 ; 31 \%)$; half of the studies resulted in practice change (9 of the 15 studies; $60 \%$ ). There were other less frequently targeted behaviors that demonstrated high success rates, including studies targeting increased knowledge or self-efficacy/confidence (4 out of 4 [100\%] effective), increasing screening/testing rates (7 out of 8 [88\%] effective), and clinical intervention/management (5 out of 6 [83\%] effective) all were described as showing positive effects.

\section{Coding interventions for specific BCTs}

Of the 48 studies included in the final analysis, 26 (54\%) contained evidence of BCTs relating to use of technology or the target behavior (Fig. 2). Seven different BCTs were identified across the 26 studies. The BCT code according to Michie et al. [17] is presented in parentheses, followed by the number of studies using each technique. The most commonly used BCT was instruction on how to perform the behavior (BCTTv1 4.1; $n=22$ ). This technique was mostly used in the context of healthcare professional decision support interventions $(n=9)$, and reminders and alerts $(n=9)$. Other techniques included feedback on behavior (BCTTv1 2.2; $n=3$ ), prompts/cues 


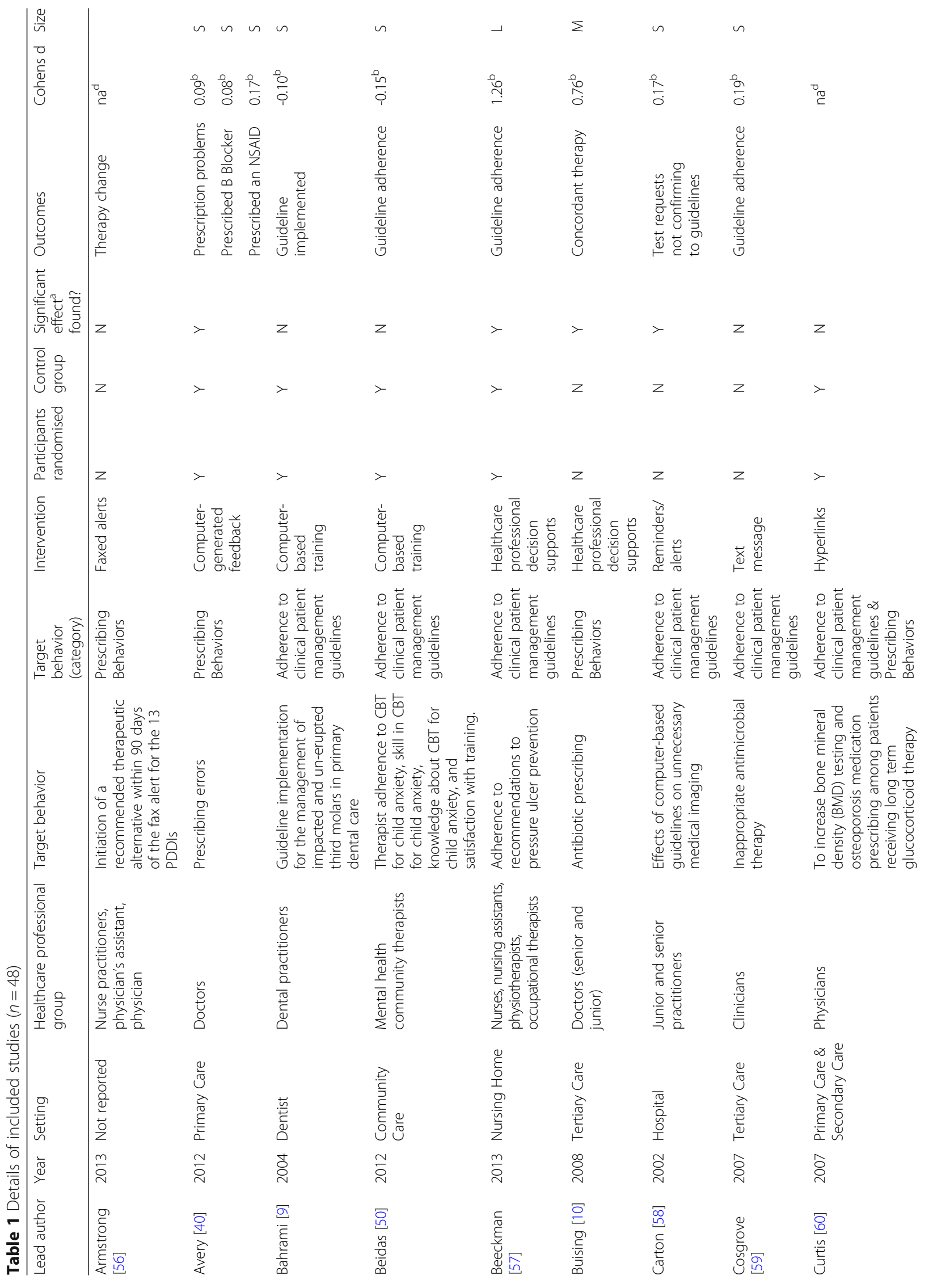




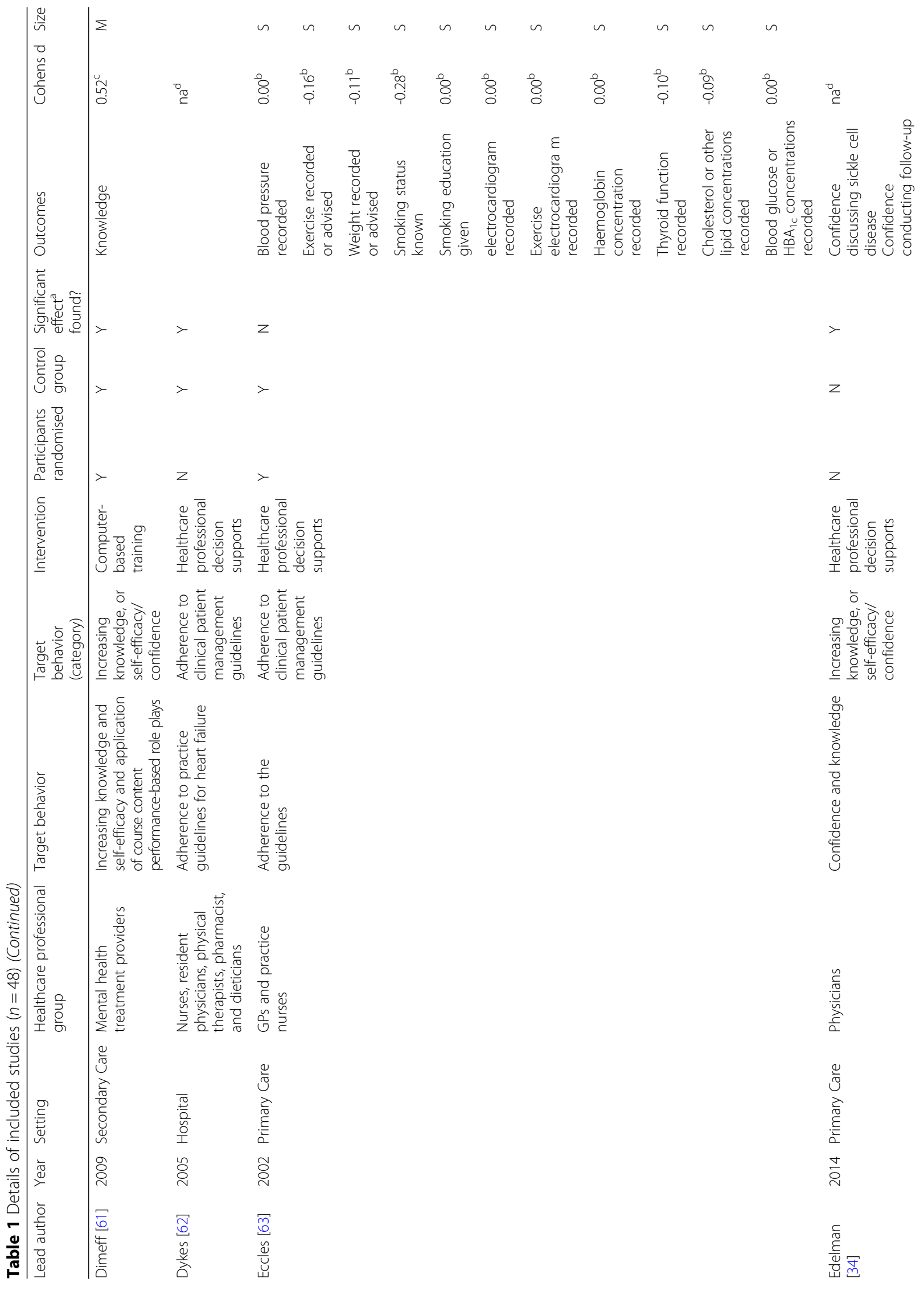




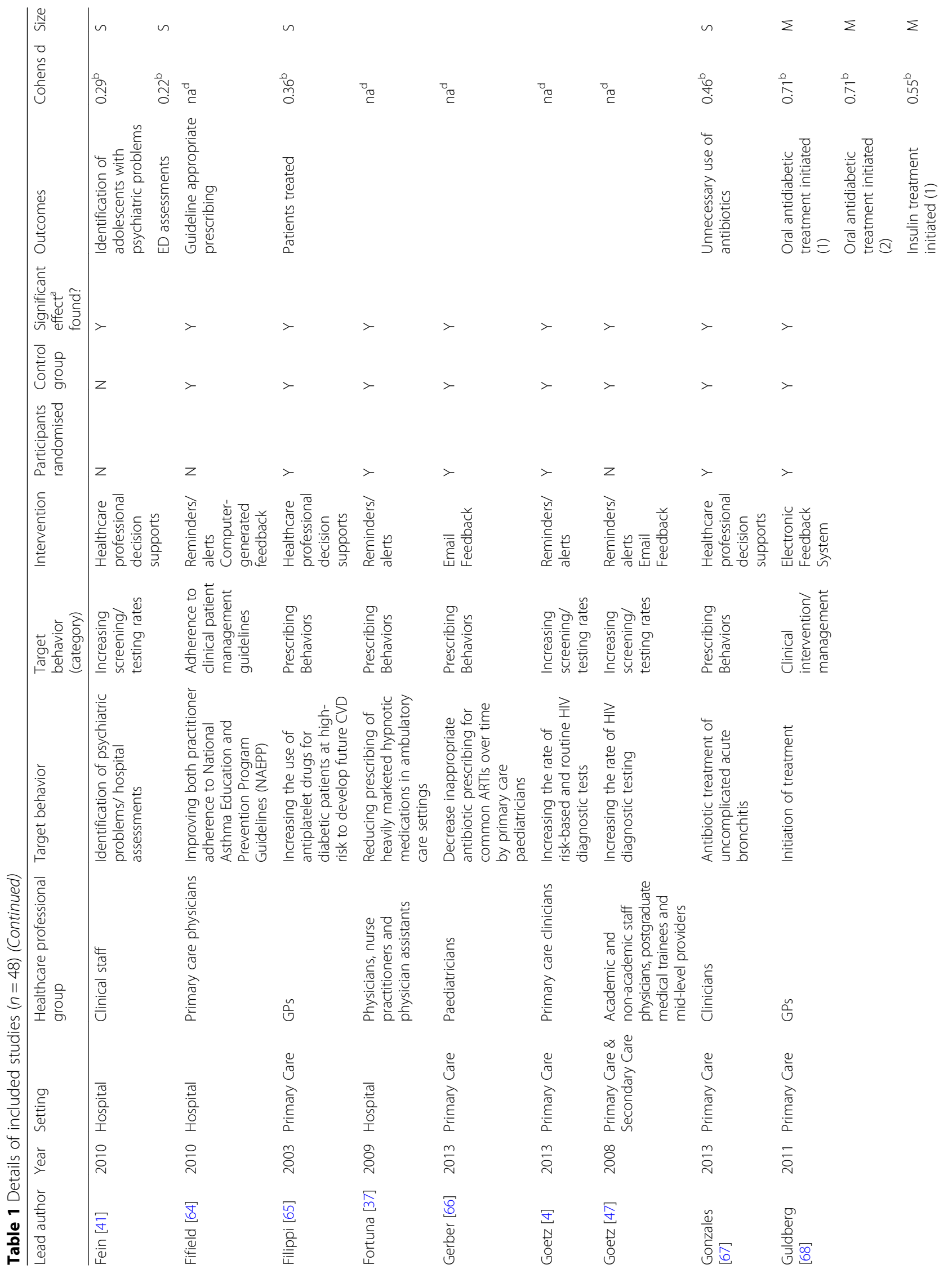




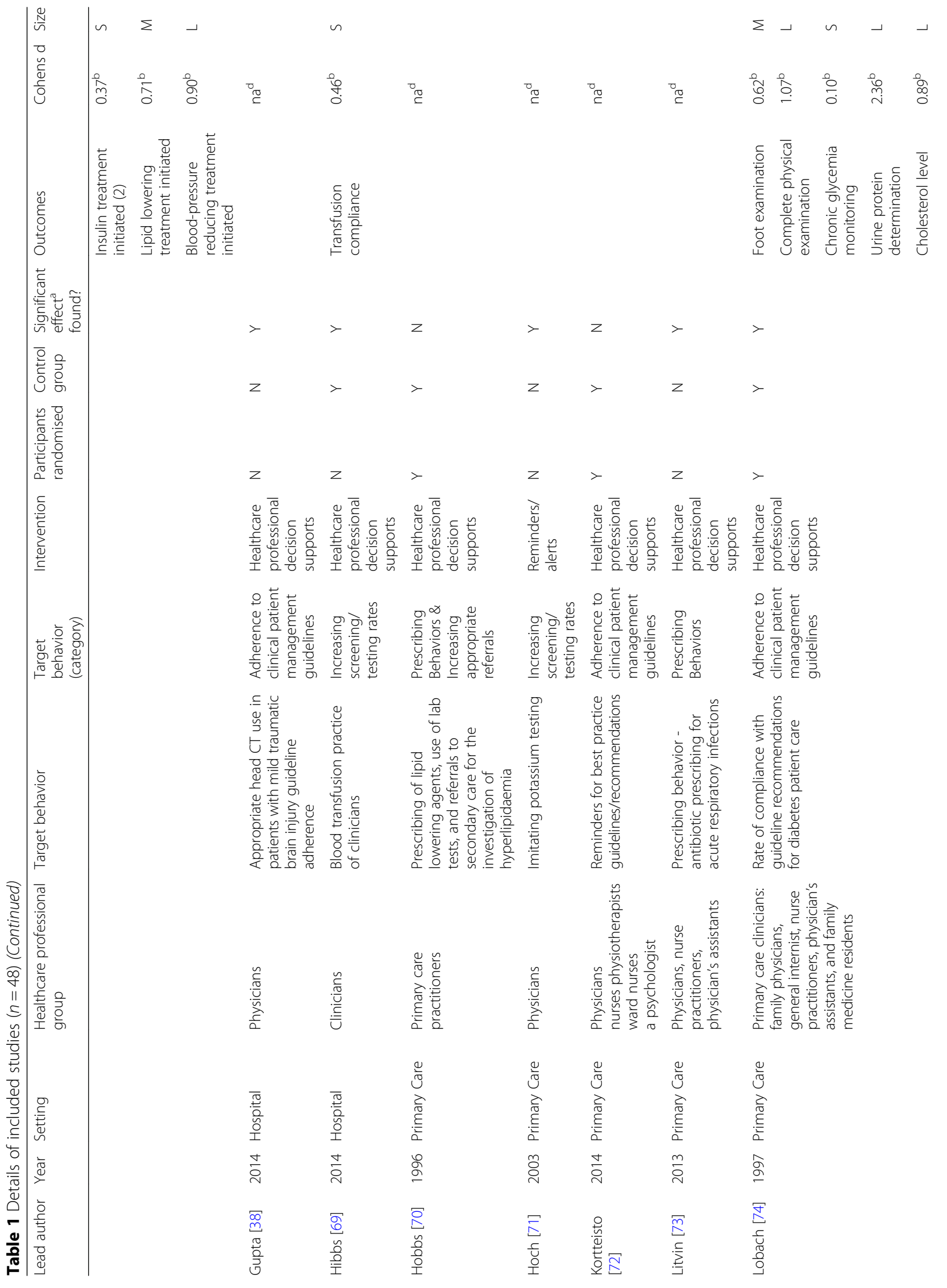




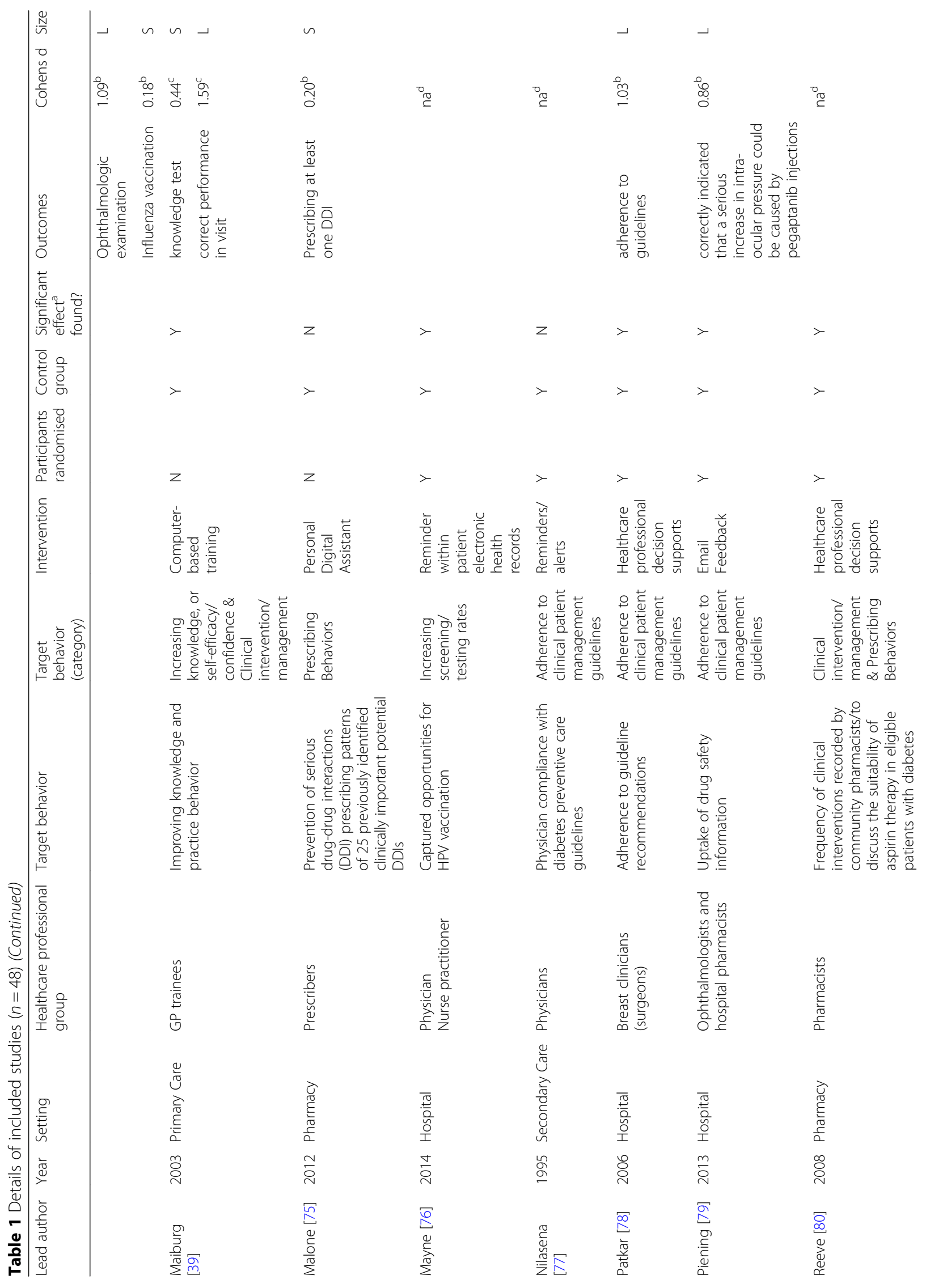




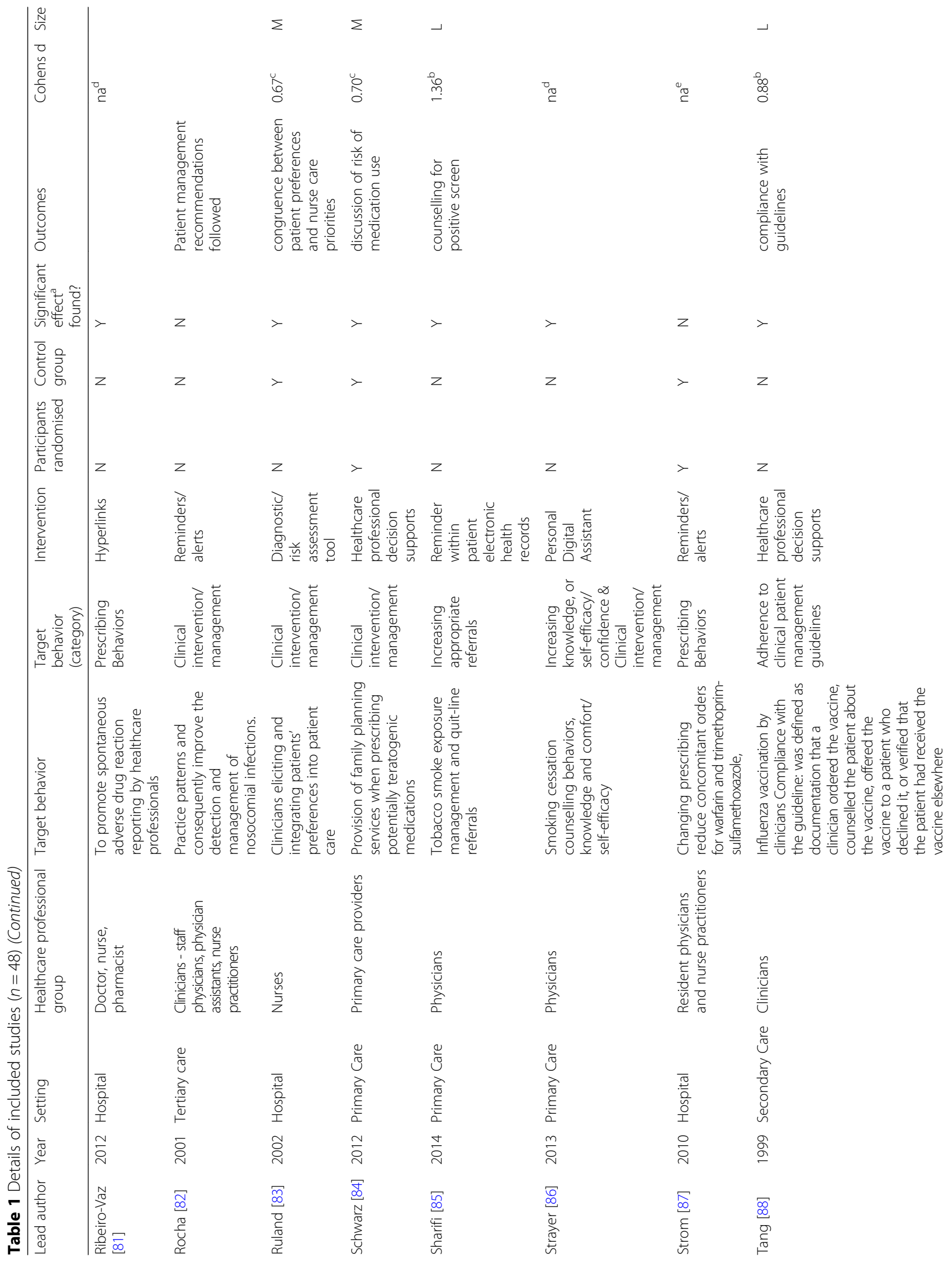




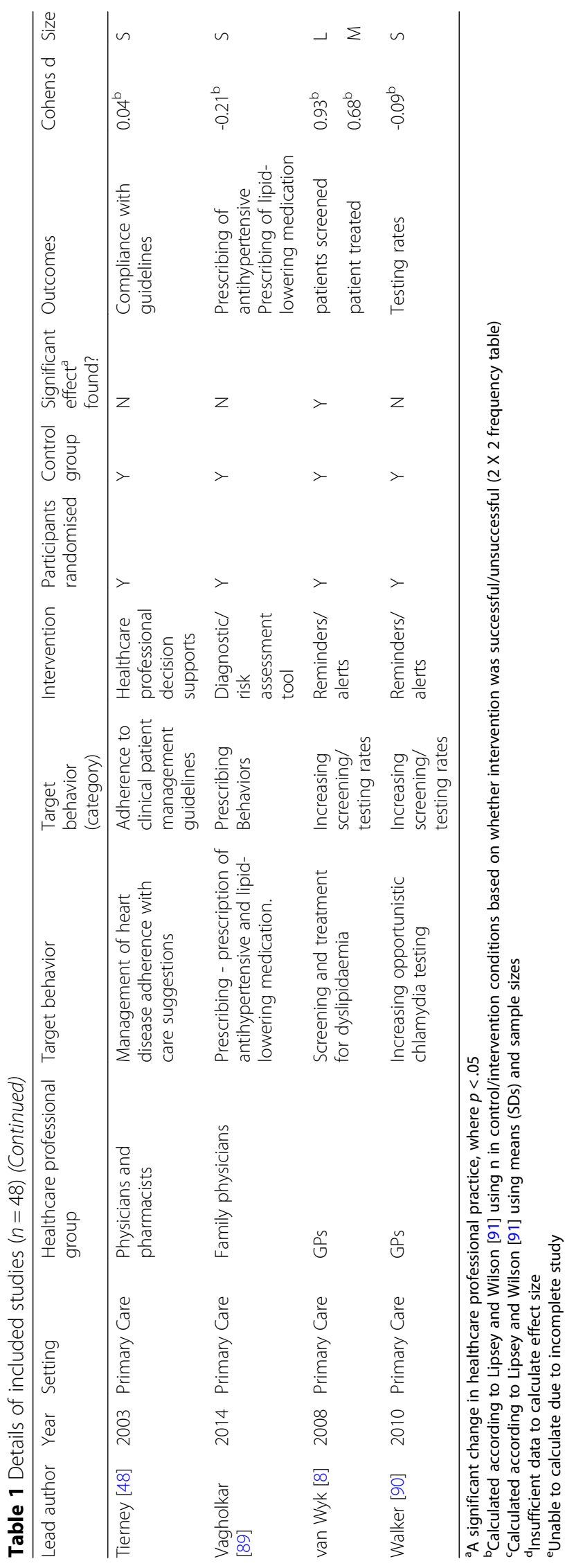


Table 2 Details of success of interventions based on type of intervention and target behavior

\begin{tabular}{|c|c|c|c|}
\hline Domain & $\begin{array}{l}\text { Number of interventions } \\
\text { in each category }\end{array}$ & $\begin{array}{l}\text { Number of effective } \\
\text { interventions }^{a}\end{array}$ & (\%) of effective studies \\
\hline \multicolumn{4}{|l|}{ Intervention type } \\
\hline Computer-generated feedback & 1 & 1 & 100 \\
\hline Email feedback & 3 & 3 & 100 \\
\hline Electronic feedback system & 1 & 1 & 100 \\
\hline Computer-based training & 4 & 2 & 50 \\
\hline Reminder system within patient electronic health records & 2 & 2 & 100 \\
\hline Healthcare professional decision support & 19 & 15 & 79 \\
\hline Hyperlinks & 2 & 1 & 50 \\
\hline Reminders/alerts & 11 & 7 & 64 \\
\hline Personal digital assistant & 2 & 1 & 50 \\
\hline Diagnostic/risk assessment tool & 2 & 1 & 33 \\
\hline Faxed alerts & 1 & 0 & 0 \\
\hline Text message & 1 & 0 & 0 \\
\hline \multicolumn{4}{|l|}{ Target behavior } \\
\hline Adherence to clinical patient management guidelines & 17 & 10 & 59 \\
\hline Prescribing behaviors & 15 & 9 & 60 \\
\hline Increasing screening/testing rates & 8 & 7 & 88 \\
\hline Clinical intervention/management & 6 & 5 & 83 \\
\hline Increasing knowledge, or self-efficacy/confidence & 4 & 4 & 100 \\
\hline Increasing appropriate referrals & 2 & 1 & 50 \\
\hline
\end{tabular}

${ }^{\mathrm{a} A}$ statistically significant change in healthcare professional practice, as described by the authors of each study included in this review

(BCTTv1 7.1; $n=2$ ), demonstration of the behavior (BCTTv1 6.1; $n=2$ ), reducing negative emotions (BCTTv1 11.2; $n=1)$, social comparison (BCTTv1 6.2; $n=1$ ), and problem solving (BCTTv1 1.2; $n=1)$.

Of the 26 studies containing evidence of BCTs, 16 studies (62\%) resulted in practice change (Fig. 2). Of these, five different BCTs were used across the 16 studies. The largest group was instruction on how to perform the behavior (BCTTv1 4.1; $n=15$ ), such as instructing healthcare professionals which medicines to prescribe [37] or requesting an appropriate clinical test [38]. This second largest group was demonstration of the behavior (BCTTv1 6.1; $n=2$ ), such as demonstrating effective clinician practice [39].

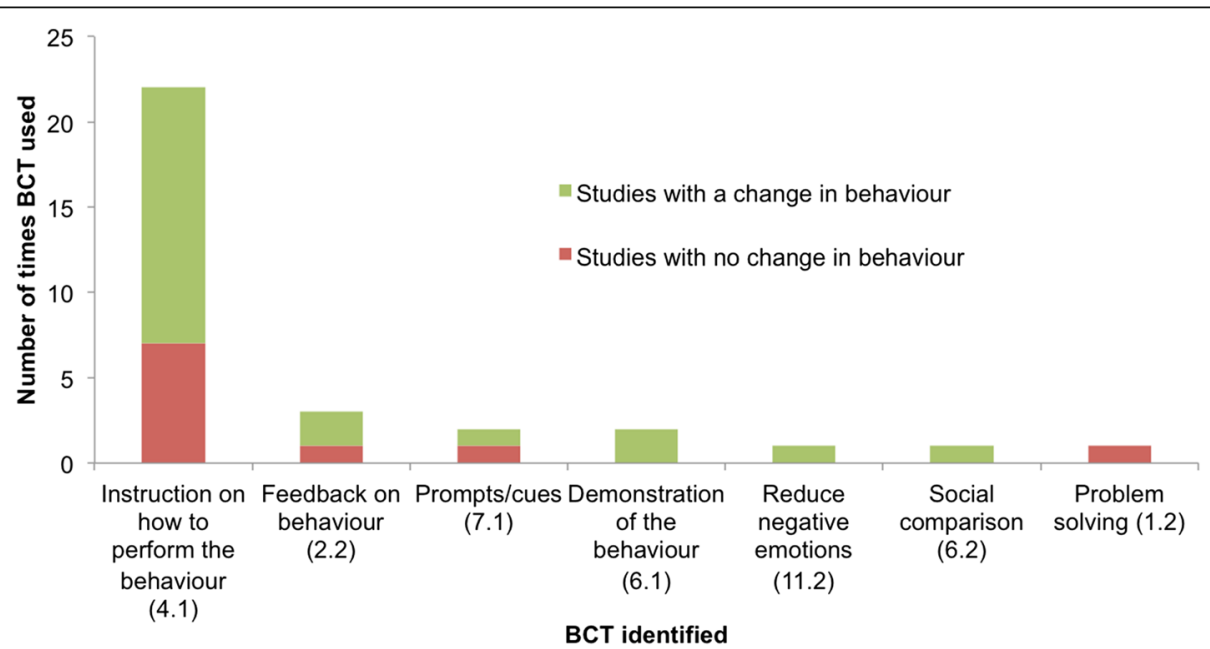

Fig. 2 Behavior change techniques identified across 26 studies according to Michie et al. [17] 


\section{Thematic analysis}

To answer review question 3 (What are the barriers and facilitators to successful implementation of such technology-based interventions in practice?), a thematic analysis was conducted to address the practicalities of implementing technology in practice. Characteristics of the 21 qualitative $(n=19)$ and quantitative $(n=2)$ studies are presented in Table 3.

Themes identified address the barriers and facilitators of implementing and delivering technology-based interventions aimed at supporting professional practice change. Four major themes were identified (summarised in Fig. 3): (1) Practice and workload issues, (2) Design, content and technical issues, (3) Role of the healthcare professional, and (4) Usability and impact on the patient care process. The numbers of papers reporting each finding are reported in parentheses, out of a possible 21 papers.

(1) Practice and workload issues

A number of contextual features (the setting in which the intervention was delivered) were highlighted; practice and workload considerations were perceived as important in the implementation of technology-based interventions. Increased workload was an issue as a result of using technology as part of everyday practice, which may disrupt the workflow of healthcare professionals $(n=4 ; 19 \%)$. Time taken to use the system was cited as a barrier to likelihood of healthcare professionals using technology $(n=5 ; 24 \%)$, suggesting a need for a more user-friendly design of technology-based interventions. However, technology was seen as a way of improving communication between healthcare professionals $(n=3 ; 14 \%)$ and improving the delivery of healthcare in practice $(n=3 ; 14 \%)$.

A key factor for the successful implementation of technology into the healthcare environment was whether the intervention met the practice/organizational goals and objectives $(n=11 ; 52 \%)$. More specifically, whether the addition of technology met current practice initiatives and could be easily integrated into existing clinical practice, and targeted organizational incentives including patient management approaches and financial incentives.

(2) Design, content and technical issues,

Features of the technology itself were also highlighted. Studies emphasised the importance of pilot testing before wide-scale usage and in particular the need to take an iterative modification approach, such as customising tools

Table 3 Details of practicalities papers $(n=21)$

\begin{tabular}{|c|c|c|c|}
\hline Lead author & Year & Country & Data collection method \\
\hline Ackerman [43] & 2013 & USA & Qualitative structured telephone surveys \\
\hline Barnett [92] & 2015 & UK & Think-aloud and semi-structured interviews \\
\hline Bokhour [93] & 2015 & USA & Qualitative semi-structured interviews \\
\hline Burns [94] & 2007 & Australia & Semi-structured interviews \\
\hline Doerr [95] & 2014 & USA & Semi-structured interviews \\
\hline Dowding [96] & 2009 & UK & In-depth semi-structured interviews \\
\hline Dryden [97] & 2012 & USA & Qualitative, in-depth semi-structured telephone interviews \\
\hline Edelman [34] & 2014 & USA & Semi-structured interviews and quantitative survey data \\
\hline Guldberg [98] & 2010 & Denmark & Group and individual semi-structured interviews \\
\hline Hains [99] & 2009 & Australia & Semi-structured interviews \\
\hline Litvin [100] & 2012 & USA & Semi-structured group interviews \\
\hline Maguire [101] & 2008 & UK & Questionnaires and semi-structured interviews \\
\hline Mandt [102] & 2010 & Norway & Focus groups \\
\hline Patterson [42] & 2004 & USA & Semi-structured interviews \\
\hline Power [103] & 2014 & Canada & Surveys \\
\hline Randell [104] & 2010 & UK & In-depth semi-structured interviews \\
\hline Rousseau [105] & 2003 & UK & Semi-structured interviews \\
\hline Saleem [106] & 2005 & USA & Qualitative field observations \\
\hline Vishwanath [107] & 2009 & USA & Surveys \\
\hline Weir [108] & 2011 & USA & Formative interviews \\
\hline Zhu [109] & 2015 & USA & Qualitative Survey \\
\hline
\end{tabular}




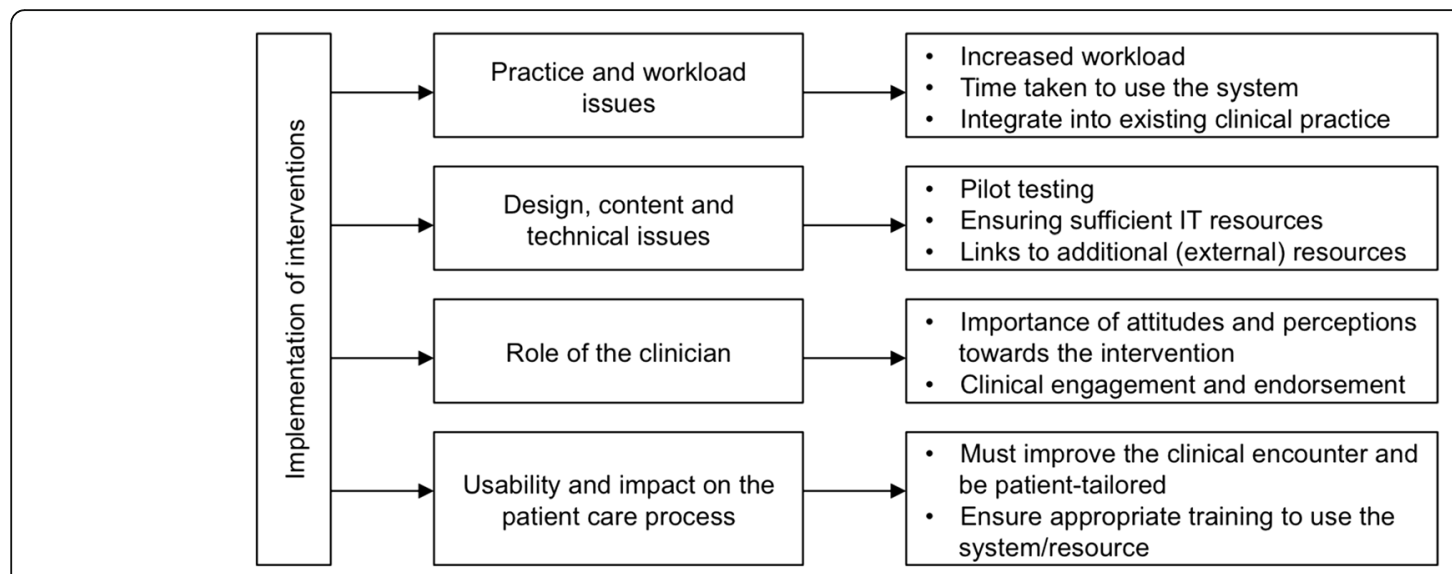

Fig. 3 Barriers and facilitators of implementing technological support interventions aimed at supporting

to the needs of the staff ( $n=5 ; 24 \%)$. Piloting may identify important technical issues acting as barriers to usage, such as insufficient access to IT resources, software updates and limitations in computer performance $(n=9 ; 43 \%)$. Where interventions included patient management guidelines, the need for consistency and reliability was highlighted. Links to external resources such as forums, risk assessment tools or patient information sources, must be used appropriately and in a way to improve the delivery of patient care $(n=8 ; 38 \%)$. Guidelines in particular must be relevant to patient management $(n=4 ; 19 \%)$.

(3) Usability and benefit for patient care.

Additional important features of the technology included accessibility to important information relevant to the clinical encounter for example medication information, hence making it an important educational resource $(n=4 ; 19 \%)$. Technology was also seen as a way of improving other aspects of the clinical encounter such as medication reviews or stimulating provider-patient discussions $(n=5 ; 24 \%)$.

An important feature was the ease of use of the technology $(n=9 ; 43 \%)$; barriers included system navigation and poor interface issues. A major factor in the uptake and acceptability of technology-based interventions was appropriate training and IT skills $(n=18 ; 86 \%)$. Specific considerations include implementing an initial learning/ familiarisation period to use the system and providing technical training for users.

\section{(4) Role of the healthcare professional}

Technology-based interventions increase healthcare professional confidence in decision making in situations of uncertainty around patient management $(n=3 ; 14 \%)$. Attitudes and perceptions of healthcare professionals towards technologies were seen as important in terms of its usage; positive attitudes were more commonly associated with uptake $(n=6 ; 29 \%)$. Two studies emphasised the importance of senior professionals endorsing and driving the use of technology as being key to its success. In particular, healthcare professional engagement with technologies was reported as being key to its implementation, such as assigning one or more groups of healthcare professionals with sole responsibility of using the system, such as practice nurses $(n=6 ; 29 \%)$.

\section{Discussion}

This review has identified key features of successful interventions with a technological component aimed to improve healthcare professional practice. Results provide insights into the characteristics of successful interventions and provide recommendations for the design and implementation of technologies based on the barriers and facilitators identified.

A summary of the key findings from the present review is presented in Table 4, which outlines successful intervention features and components, effective BCTs used in interventions, and the barriers and facilitators in relation to implementing interventions. The most successful technological intervention was healthcare professional decision support, suggesting this may have an important role to play in clinical practice. The most common intervention setting was within primary care; however more practice change occurred in hospitals. This suggests two areas for future research. First, it is necessary to understand how the hospital setting, a key place in which deliver behavior change interventions aimed at supporting healthcare professional practice, such as prescribing practices [40] or screening of health conditions [41] can be utilised to facilitate delivery of technological interventions. Second, research is needed to find ways of overcoming the barriers that exist within primary care settings, particularly those identified by our thematic analysis. For example, organizational/structural 
Table 4 Summary of findings of the important factors of implementation of technological interventions aimed at improving professional practice

\begin{tabular}{|c|c|c|c|c|}
\hline Construct & Topic & Specific features / recommendations & References & $\begin{array}{l}\text { Barrier / } \\
\text { facilitator }\end{array}$ \\
\hline \multirow[t]{3}{*}{ What works } & \multirow[t]{2}{*}{ Type of intervention } & Healthcare professional decision support & $\begin{array}{l}{[10,34,38,41,57,62,65,67} \\
69,73,74,78,80,84,88]\end{array}$ & \\
\hline & & Reminders and alerts & {$[4,8,37,47,58,64,71]$} & \\
\hline & $\mathrm{BCTs}$ & $\begin{array}{l}\text { Instruction on how to perform the behaviour } \\
\text { (BCTTV1 4.1) }\end{array}$ & $\begin{array}{l}{[8,10,37-40,47,50,57,58,} \\
64,74,78,86]\end{array}$ & \\
\hline \multirow[t]{7}{*}{$\begin{array}{l}\text { For whom interventions } \\
\text { work for }\end{array}$} & \multirow[t]{5}{*}{$\begin{array}{l}\text { Target healthcare } \\
\text { professional behaviour }\end{array}$} & $\begin{array}{l}\text { Adherence to clinical guidelines for patient } \\
\text { management }\end{array}$ & {$[38,57,58,62,64,74,78,79,88]$} & \\
\hline & & Prescribing behaviours & {$[10,37,40,65-67,73,80,81]$} & \\
\hline & & Increasing knowledge or self-efficacy / confidence & {$[34,39,86,61]$} & \\
\hline & & Increasing screening / testing rates & {$[4,8,41,47,69,71,76]$} & \\
\hline & & Clinical intervention / management & {$[68,80,83,84,86]$} & \\
\hline & \multirow[t]{2}{*}{$\begin{array}{l}\text { Target healthcare } \\
\text { professional }\end{array}$} & GPs & $\begin{array}{l}{[4,8,10,34,37,39,40,47,64-68,} \\
71,73,74,84-86]\end{array}$ & \\
\hline & & $\begin{array}{l}\text { Multiple healthcare professionals (more than two } \\
\text { different types of healthcare professional) }\end{array}$ & $\begin{array}{l}{[37,41,47,57,62,73,74,76,79,} \\
81]\end{array}$ & \\
\hline \multirow[t]{20}{*}{$\begin{array}{l}\text { Under what } \\
\text { circumstances }\end{array}$} & \multirow[t]{6}{*}{$\begin{array}{l}\text { Role of the healthcare } \\
\text { professional }\end{array}$} & Increases confidence in decision making & {$[43,96,103]$} & Facilitator \\
\hline & & $\begin{array}{l}\text { Attitudes and perceptions towards technology } \\
\text { important in terms of uptake and usage }\end{array}$ & {$[43,99-102,107]$} & Facilitator \\
\hline & & Importance of endorsement from senior peers & {$[99,104]$} & Facilitator \\
\hline & & Engagement important factor for implementation & {$[95,100,104]$} & Facilitator \\
\hline & & Assigning responsibility to using the system & {$[34,100,106]$} & Facilitator \\
\hline & & & & Facilitator \\
\hline & \multirow[t]{6}{*}{$\begin{array}{l}\text { Design, content and } \\
\text { technical issues }\end{array}$} & $\begin{array}{l}\text { Pilot testing - iterative modification to meet staff } \\
\text { needs }\end{array}$ & {$[100,101,104,106,108]$} & Facilitator \\
\hline & & Insufficient access to IT resources & {$[34,92,99,104]$} & Barrier \\
\hline & & Physical location of computer & {$[94,100,106]$} & Barrier \\
\hline & & $\begin{array}{l}\text { Technical issues such as computer performance and } \\
\text { software updates }\end{array}$ & $\begin{array}{l}{[94,95,98,100,102,104,105} \\
108]\end{array}$ & Barrier \\
\hline & & Links to external patient information resources important & {$[92,95,99]$} & Facilitator \\
\hline & & $\begin{array}{l}\text { Links to patient guidelines must be readily available, } \\
\text { consistent and relevant }\end{array}$ & {$[43,97-100]$} & Facilitator \\
\hline & \multirow[t]{6}{*}{$\begin{array}{l}\text { Usability and benefit } \\
\text { for patient care }\end{array}$} & $\begin{array}{l}\text { Provides access to important information relevant } \\
\text { to the clinical encounter }\end{array}$ & {$[98,99,103,109]$} & Facilitator \\
\hline & & Technology / interface must not be difficult to use & {$[43,93,96,97,99,104-106,109]$} & Barrier \\
\hline & & Technical training for staff & {$[34,42,99-101,103-105,107,108]$} & Facilitator \\
\hline & & $\begin{array}{l}\text { Importance of a learning period / time for } \\
\text { familiarisation of the technology }\end{array}$ & {$[95-98,108]$} & Facilitator \\
\hline & & $\begin{array}{l}\text { Considers complexities of individual patients } \\
\text { (for example patients with specific conditions, } \\
\text { or comorbidities) }\end{array}$ & {$[42,43,97,105]$} & Facilitator \\
\hline & & Helps facilitate discussions with patients & {$[100,102]$} & Facilitator \\
\hline & \multirow[t]{2}{*}{$\begin{array}{l}\text { Practice and } \\
\text { workload issues }\end{array}$} & $\begin{array}{l}\text { Use of technology increases workload and may } \\
\text { cause disruption }\end{array}$ & {$[34,42,97,106]$} & Barrier \\
\hline & & $\begin{array}{l}\text { Time taken to use the system / requirement of } \\
\text { additional staff members }\end{array}$ & {$[34,93,98-100]$} & Barrier \\
\hline
\end{tabular}


Table 4 Summary of findings of the important factors of implementation of technological interventions aimed at improving professional practice (Continued)

\begin{tabular}{|c|c|c|c|c|}
\hline Construct & Topic & Specific features / recommendations & References & $\begin{array}{l}\text { Barrier / } \\
\text { facilitator }\end{array}$ \\
\hline & & $\begin{array}{l}\text { Improves communication between healthcare } \\
\text { professionals }\end{array}$ & {$[92,98,103]$} & Facilitator \\
\hline & & Must be easily integrated into day-to-day workload & {$[34,43,97,106]$} & Facilitator \\
\hline & & $\begin{array}{l}\text { Technology aligns with current practice initiatives, } \\
\text { and wider organisational context }\end{array}$ & {$[43,92,95,98,105,108]$} & Facilitator \\
\hline
\end{tabular}

and logistical barriers such as workload and time pressures are often cited as challenges in primary care settings [42, 43], which may consequently influence the effectiveness of interventions. Our review also suggests financial incentives may be a way of engaging healthcare professionals with interventions. Whilst recent evidence suggests financial incentives may not influence long-term practice habits [44], our findings suggest this may be used to engage clinicians in technology-based interventions and therefore focusing on improving uptake.

The barriers and facilitators identified in this review are consistent with theoretical approaches to understanding implementation of interventions. Normalisation Process Theory $[45,46]$ can be used to understand how technological interventions become embedded in clinical practice. BCTs can be applied to demonstrate how interventions can be delivered in practice to facilitate implementation of technological interventions. Thus, four key recommendations can be made. First, it is necessary to understand how healthcare professionals make sense of the intervention in question. Consequently, technological interventions must have a clear function and meet organizational initiatives (coherence domain; e.g. instruction on how to perform the behaviour [BCTTv1 4.1]). Second, healthcare professionals must be actively engaged with technological interventions, which must be endorsed by key professionals within organisations, (cognitive participation domain; e.g. social support [BCTTv1 3.1]). Third, interventions must be easily integrated into clinical practice by: (a) complementing existing workloads of healthcare professionals; and (b) considering the diversity in terms of the setting in which they are delivered, the recipient of the intervention, and the target behaviour (collective action domain; e.g. action planning [BCTTv1 1.4]). Fourth, ensure that interventions are appraised by the recipients as having a benefit in terms of improving the patient encounter (reflexive monitoring domain; e.g. self-monitoring of outcome(s) of behaviour [BCTTv1 2.4]).

Our review shows that General Practitioners (GPs) are the most commonly targeted healthcare professional for technology-based interventions, and such interventions demonstrate the highest proportion of success in achieving behavior change. The role of the GP may be particularly important in understanding how technological approaches can be used to support professional practice. Of the 24 studies aimed at GPs, eight studies used computerised decision support and a further eight used reminders and alerts. The second largest group involved targeting multiple healthcare professionals, however only half of the studies resulted in behavior change. This is particularly important as part of the healthcare professional role involves referral and signposting to other healthcare professionals, where appropriate, and is recognized in primary care training strategies $[5,6]$. One possible application of technological support, suggested by our thematic analysis, is to use technology to improve the communication between multiple healthcare professionals regarding patient management [11].

\section{Use of behaviour change techniques in interventions}

Use of recognized behavior change techniques [17] was identified in a number of studies. The most commonly used BCT was instruction on how to perform the behavior in the context of instructions from decision support systems, reminders and alerts. This technique may be particularly important for supporting healthcare professional clinical practice in the context of a technological intervention, which often involves tasks related to clinical decision making, such as making referrals and conducting health checks $[5,38,47,48]$.

When using BCTs, there were more studies resulting in healthcare professional behavior change than those showing no change. Given that the BCT framework is still in its infancy, interventions must apply the techniques to important areas of clinical practice (such as increasing appropriate screening and more appropriate medicine prescribing practices). The use of theory offers valuable insights both in terms of understanding and supporting practice change $[19,49]$, and as a framework to guide interventions. Our review has provided encouraging findings supporting the use of BCTs as part of technology-based interventions supporting healthcare professional practice change. Findings suggest that BCTs can be effective across a range of diverse interventions, target behaviours, and healthcare professionals groups. The BCT instruction on how to perform the behaviour, effective in 15 studies, was implemented across prescribing 
behaviours (e.g.), adherence to patient management guidelines (e.g. [50]), and increasing screening rates (e.g.), and found to be effective when delivered to doctors, therapists [50], nurses, and surgeons. Identifying effective BCTs in this way allows the opportunity to deliver interventions aiming to change healthcare professional practice shown to be effective across a range of diverse contexts. Given that 22 of the 48 studies included in this review did not contain any evidence of BCTs, there is considerable scope for future research to develop interventions that include BCTs. This may involve targeting known psychological constructs involved in behavior change, using established as well as emerging frameworks specifically relating to implementation of interventions [51-53].

\section{Strengths and limitations of this review}

Although there are a number of systematic reviews [11$15,54]$ that examine the effectiveness of individual types of technology-based interventions aimed at healthcare professionals, this is the first attempt to synthesise evidence across all interventions that include a technological component, and the factors involved in implementation of interventions. We have synthesised the findings from across a diverse range of intervention contexts and settings, and presented a series of barriers and facilitators that are shared across healthcare behaviours and diverse professional groups. The advantage of this approach is this provides a series of recommendations concerning implementation of interventions, and an opportunity for behaviour change interventions to be delivered at scale, targeting multiple healthcare professional groups working in different healthcare settings. This is also an attempt to move beyond the most commonly researched interventions and provide a wider understanding of both intervention function and content. The current review extends the findings of previous reviews by: (1) identifying specific features associated with successful interventions, (2) highlighting opportunities to improve the design of technologies by incorporating known BCTs; and (3) identifying the barriers and facilitators to successful implementation. Future reviews would benefit from including an analysis of patient outcomes, particularly whether changes in healthcare professional practice as a consequence of implementing technological interventions translates into positive patient outcomes.

The realist method of literature review was chosen to guide the present review in order to understand a large and complex literature, with the qualitative findings advancing our quantitative findings by providing an explanatory framework about why and how technological interventions work. This level of detail would not have been possible to identify using the Cochrane style of systematic review methods. Whilst we sought to extract effect sizes for included studies, due to the varied reporting of study results, and in the absence of the relevant statistical information such as $p$ values and sample sizes, it was only possible to calculate effect sizes for a small number of papers. Further, due to the range of outcomes obtained, and often multiple outcomes from individual studies, a direct comparison between groups was not possible.

\section{Conclusions}

Technological approaches to improving healthcare professional practice provide opportunities to address challenges in multiple areas of clinical practice [55]. Healthcare professional decision support interventions, when developed using recognized psychological theory such as providing instruction on how to implement interventions, show considerable promise. Interventions must also address known organizational challenges associated with specific settings, as well as focusing on efficiency and user-friendly design content, whilst ensuring interventions complement the day-to-day workload and current knowledge and skillset of the target healthcare professional. Understanding the most important contextual features, and how to apply theoretical insights known to change behavior can all contribute to the design and successful implementation of technologies aiming to directly influence the clinical management of patients.

\section{Additional files} Additional file 1: Search strategy. (DOCX $15 \mathrm{~kb}$ )
Additional file 2: Flow diagram of abstract screening process for each
analysis component. (DOCX $22 \mathrm{~kb}$ )

Additional file 3: Forest plot displaying Cohen's d and confidence intervals for study outcomes. (DOCX $34 \mathrm{~kb}$ )

\section{Abbreviations}

$\mathrm{BCT}$ : Behaviour change technique; BCTTV1: Behaviour change technique taxonomy version 1; CINAHL: Cumulative index to nursing and allied health literature; GP: General practitioner; IT: Information technology; MeSH: Medical subject heading

\section{Funding}

This work was funded through a University Research Institute Pump Priming Programme and supported by the NIHR Manchester Biomedical Research Centre and the NIHR Greater Manchester Patient Safety Translational Research Centre.

Availability of data and materials

Please contact author for data requests.

Authors' contributions

CK, MPT, JH and CJA designed and conceived the review. CK conducted the search and CK and MPT selected articles for inclusion according to the inclusion/exclusion criteria. CK conducted extraction of the data, CK and MPT conducted analysis. CK drafted the manuscript and revised accordingly based on all co-author comments. All authors approved the final version.

Ethics approval and consent to participate Not applicable. 


\section{Consent for publication}

Not applicable.

\section{Competing interests}

The authors declare that they have no competing interests.

\section{Publisher's Note}

Springer Nature remains neutral with regard to jurisdictional claims in published maps and institutional affiliations.

\section{Author details}

${ }^{1}$ Manchester Centre for Health Psychology, Division of Psychology and Mental Health, School of Health Sciences, Faculty of Biology, Medicine and Health, University of Manchester, Manchester Academic Health Science Centre, Coupland 1 Building, Oxford Road, Manchester M13 9PL, UK. ${ }^{2}$ Division of Medical Education, School of Medical Sciences, Faculty of Biology, Medicine and Health, University of Manchester, Manchester Academic Health Science Centre, Oxford Road, Manchester M13 9PL, UK. ${ }^{3}$ Division of Pharmacy and Optometry, School of Health Sciences, Faculty of Biology, Medicine and Health, University of Manchester, Manchester Academic Health Science Centre, Stopford Building, Oxford Road, Manchester M13 9PL, UK. ${ }^{4} \mathrm{NIHR}$ Manchester Biomedical Research Centre, Manchester University NHS Foundation Trust, Manchester Academic Health Science Centre, Manchester M13 9PL, UK. ${ }^{5}$ NIHR Greater Manchester Patient Safety Translational Research Centre, Manchester, UK.

Received: 27 March 2018 Accepted: 27 September 2018 Published online: 07 November 2018

\section{References}

1. National Institute for Health and Care Excellence. Behaviour change: individual approaches (PH49). London: NICE; 2014.

2. Ashcroft DM, et al. Prevalence, nature, severity and risk factors for prescribing errors in hospital inpatients: prospective study in 20 UK hospitals. Drug Saf. 2015;38(9):833-43.

3. Mant D. Health checks and screening: what works in general practice? $\mathrm{Br} J$ Gen Pract. 2014;64(627):493-4.

4. Goetz MB, et al. Central implementation strategies outperform local ones in improving HIV testing in Veterans Healthcare Administration facilities. J Gen Intern Med. 2013;28(10):1311-7.

5. National Health Service (NHS) Yorkshire and the Humber. Prevention and Lifestyle Behaviour Change: A Competence Framework. Yorkshire and the Humber: NHS; 2010

6. General Medical Council (GMC). Tomorrow's doctors: outcomes and standards for undergraduate medical education: London, GMC; 2009.

7. Ross $\mathrm{S}$, et al. Perceived causes of prescribing errors by junior doctors in hospital inpatients: a study from the PROTECT programme. BMJ Qual Saf. 2013;22(2):97-102.

8. van Wyk JT, et al. Electronic alerts versus on-demand decision support to improve dyslipidemia treatment: a cluster randomized controlled trial. Circulation. 2008;117(3):371-8.

9. Bahrami $\mathrm{M}$, et al. Effectiveness of strategies to disseminate and implement clinical guidelines for the management of impacted and unerupted third molars in primary dental care, a cluster randomised controlled trial. $\mathrm{Br}$ Dent J. 2004;197(11):691-6.

10. Buising $\mathrm{KL}$, et al. Improving antibiotic prescribing for adults with community acquired pneumonia: does a computerised decision support system achieve more than academic detailing alone? - A time series analysis. BMC Medical Informatics and Decision Making. 2008;8:35.

11. Goyder C, et al. Email for clinical communication between healthcare professionals. Cochrane Database Syst Rev. 2015;2:CD007979.

12. Fiander $\mathrm{M}$, et al. Interventions to increase the use of electronic health information by healthcare practitioners to improve clinical practice and patient outcomes. Cochrane Database Syst Rev. 2015;3:CD004749.

13. Arditi $C$, et al. Computer-generated reminders delivered on paper to healthcare professionals; effects on professional practice and health care outcomes. Cochrane Database Syst Rev. 2012;12:CD001175.

14. Campanella $P$, et al. The impact of electronic health records on healthcare quality: a systematic review and meta-analysis. Eur J Pub Health. 2016;26(1): $60-4$.
15. Brown $\mathrm{CL}$, et al. A systematic review of the types and causes of prescribing errors generated from using computerized provider order entry systems in primary and secondary care. J Am Med Inform Assoc. 2016.

16. Gardner B, et al. Using theory to synthesise evidence from behaviour change interventions: the example of audit and feedback. Soc Sci Med. 2010;70(10):1618-25.

17. Michie $\mathrm{S}$, et al. The behavior change technique taxonomy ( $\mathrm{v} 1)$ of 93 hierarchically clustered techniques: building an international consensus for the reporting of behavior change interventions. Ann Behav Med. 2013;46(1): $81-95$.

18. Eccles $M$, et al. Changing the behaviour of healthcare professionals: the use of theory in promoting the uptake of research findings. J Clin Epidemiol. 2005:58(2):107-12.

19. Eccles MP, et al. Explaining clinical behaviors using multiple theoretical models. Implement Sci. 2012;7(1):1-13.

20. Ross J, et al. Factors that influence the implementation of e-health: a systematic review of systematic reviews (an update). Implement Sci. 2016; 11:146.

21. Rycroft-Malone J, et al. Realist synthesis: illustrating the method for implementation research. Implement Sci. 2012;7:33.

22. Pawson $\mathrm{R}$. The science of evaluation: a realist manifesto. London: SAGE Publication Ltd.; 2013.

23. Mays N, Pope C, Popay J. Systematically reviewing qualitative and quantitative evidence to inform management and policy-making in the health field. J Health Serv Res Policy. 2005;10(Suppl 1):6-20.

24. Tsang JY, et al. Understanding the implementation of interventions to improve the management of chronic kidney disease in primary care: a rapid realist review. Implement Sci. 2016;11:47.

25. Pearson $\mathrm{M}$, et al. Implementing health promotion programmes in schools: a realist systematic review of research and experience in the United Kingdom. Implement Sci. 2015;10:149.

26. Vassilev I, et al. Assessing the implementability of telehealth interventions for self-management support: a realist review. Implement Sci. 2015;10(1):59.

27. Pearson $\mathrm{M}$, et al. Using realist review to inform intervention development: methodological illustration and conceptual platform for collaborative care in offender mental health. Implement Sci. 2015;10:134.

28. Craig P, et al. Developing and evaluating complex interventions: the new Medical Research Council guidance. 2008;337.

29. Greenhalgh T, et al. Protocol_-realist and meta-narrative evidence synthesis: evolving standards (RAMESES). BMC Med Res Methodol. 2011;11:115.

30. Pawson $\mathrm{R}$, et al. Realist review - a new method of systematic review designed for complex policy interventions. J Health Serv Res Policy. 2005; 10(Suppl 1):21-34

31. Michie $\mathrm{S}$, et al. Effective techniques in healthy eating and physical activity interventions: a meta-regression. Health Psychol. 2009;28(6):690-701.

32. Bazeley P, Jackson K. In: Bazeley P, Jackson K, editors. Qualitative data analysis with NVivo, London: Sage Publications Limited.; 2013.

33. Kastner $\mathrm{M}$, et al. What is the most appropriate knowledge synthesis method to conduct a review? Protocol for a scoping review. BMC Med Res Methodol. 2012;12:114

34. Edelman EA, et al. Evaluation of a novel electronic genetic screening and clinical decision support tool in prenatal clinical settings. Matern Child Health J. 2014;18(5):1233-45.

35. Osheroff JA, et al. A roadmap for national action on clinical decision support. J Am Med Inform Assoc. 2007:14(2):141-5.

36. Cohen J. Statistical power analysis for the behavioural sciences. Hillside: Lawrence Earlbaum Associates; 1988.

37. Fortuna RJ, et al. Reducing the prescribing of heavily marketed medications: a randomized controlled trial. J Gen Intern Med. 2009;24(8):897-903.

38. Gupta A, et al. Effect of clinical decision support on documented guideline adherence for head CT in emergency department patients with mild traumatic brain injury. J Am Med Inform Assoc. 2014;21(e2):e347-51.

39. Maiburg $\mathrm{BH}$, et al. Controlled trial of effect of computer-based nutrition course on knowledge and practice of general practitioner trainees. Am J Clin Nutr. 2003;77(4 Suppl):1019S-24S.

40. Avery AJ, et al. A pharmacist-led information technology intervention for medication errors (PINCER): a multicentre, cluster randomised, controlled trial and cost-effectiveness analysis. Lancet. 2012:379(9823):1310-9.

41. Fein JA, et al. Feasibility and effects of a web-based adolescent psychiatric assessment administered by clinical staff in the pediatric emergency department. Arch Pediatr Adolesc Med. 2010;164(12):1112-7. 
42. Patterson ES, et al. Human factors barriers to the effective use of ten HIV clinical reminders. J Am Med Inform Assoc. 2004;11(1):50-9.

43. Ackerman SL, et al. One size does not fit all: evaluating an intervention to reduce antibiotic prescribing for acute bronchitis. BMC Health Serv Res. 2013;13:462.

44. Chauhan BF, et al. Behavior change interventions and policies influencing primary healthcare professionals' practice-an overview of reviews. Implement Sci. 2017;12(1):3.

45. Murray E, et al. Normalisation process theory: a framework for developing, evaluating and implementing complex interventions. BMC Med. 2010;8:63.

46. May CR, et al. Development of a theory of implementation and integration: normalization process theory. Implement Sci. 2009;4:29.

47. Goetz MB, et al. A system-wide intervention to improve HIV testing in the Veterans Health Administration. J Gen Intern Med. 2008;23(8):1200-7.

48. Tierney WM, et al. Effects of computerized guidelines for managing heart disease in primary care. J Gen Intern Med. 2003;18(12):967-76.

49. Johnson MJ, May CR. Promoting professional behaviour change in healthcare: what interventions work, and why? A theory-led overview of systematic reviews. BMJ Open. 2015;5(9):e008592.

50. Beidas RS, et al. Training and consultation to promote implementation of an empirically supported treatment: a randomized trial. Psychiatr Serv. 2012; 63(7):660-5.

51. Michie S, van Stralen MM, West R. The behaviour change wheel: a new method for characterising and designing behaviour change interventions. Implement Sci. 2011;6:42.

52. Hrisos S, et al. An intervention modelling experiment to change GPs' intentions to implement evidence-based practice: using theory-based interventions to promote GP management of upper respiratory tract infection without prescribing antibiotics \#2. BMC Health Serv Res. 2008;8:10.

53. Presseau J, et al. Reflective and automatic processes in health care professional behaviour: a dual process model tested across multiple behaviours. Ann Behav Med. 2014;48(3):347-58.

54. Shojania $K G$, et al. Effect of point-of-care computer reminders on physician behaviour: a systematic review. CMAJ. 2010;182(5):E216-25.

55. Shojania KG, et al. The effects of on-screen, point of care computer reminders on processes and outcomes of care. Cochrane Database Syst Rev. 2009;3:CD001096.

56. Armstrong EP, et al. Evaluation of a drug-drug interaction: fax alert intervention program. BMC Med Inform Decis Mak. 2013;13:32.

57. Beeckman $D$, et al. A multi-faceted tailored strategy to implement an electronic clinical decision support system for pressure ulcer prevention in nursing homes: a two-armed randomized controlled trial. Int J Nurs Stud. 2013;50(4):475-86

58. Carton $\mathrm{M}$, et al. Assessment of radiological referral practice and effect of computer-based guidelines on radiological requests in two emergency departments. Clin Radiol. 2002;57(2):123-8.

59. Cosgrove SE, et al. Impact of different methods of feedback to clinicians after postprescription antimicrobial review based on the centers for disease control and prevention's 12 steps to prevent antimicrobial resistance among hospitalized adults. Infect Control Hosp Epidemiol. 2007;28(6):641-6.

60. Curtis JR, et al. Challenges in improving the quality of osteoporosis care for long-term glucocorticoid users: a prospective randomized trial. Arch Intern Med. 2007;167(6):591-6.

61. Dimeff $L A$, et al. Which training method works best? A randomized controlled trial comparing three methods of training clinicians in dialectical behavior therapy skills. Behav Res Ther. 2009:47(11):921-30.

62. Dykes PC, et al. Clinical practice guideline adherence before and after implementation of the HEARTFELT (HEART Failure Effectiveness \& Leadership Team) intervention. J Cardiovasc Nurs. 2005;20(5):306-14.

63. Eccles $M$, et al. Effect of computerised evidence based guidelines on management of asthma and angina in adults in primary care: cluster randomised controlled trial. BMJ. 2002;325(7370):941.

64. Fifield J, et al. Improving pediatric asthma control among minority children participating in medicaid: providing practice redesign support to deliver a chronic care model. J Asthma. 2010;47(7):718-27.

65. Filippi $A$, et al. Effects of an automated electronic reminder in changing the antiplatelet drug-prescribing behavior among Italian general practitioners in diabetic patients: an intervention trial. Diabetes Care. 2003;26(5):1497-500.

66. Gerber JS, et al. Effect of an outpatient antimicrobial stewardship intervention on broad-spectrum antibiotic prescribing by primary care pediatricians: a randomized trial. JAMA. 2013;309(22):2345-52.
67. Gonzales R, et al. A cluster randomized trial of decision support strategies for reducing antibiotic use in acute bronchitis. JAMA Intern Med. 2013; 173(4):267-73.

68. Guldberg TL, et al. Improved quality of type 2 diabetes care following electronic feedback of treatment status to general practitioners: a cluster randomized controlled trial. Diabet Med. 2011;28(3):325-32.

69. Hibbs SP, et al. The impact of electronic decision support and electronic remote blood issue on transfusion practice. Transfus Med. 2014;24(5):274-9.

70. Hobbs FD, et al. A prospective controlled trial of computerized decision support for lipid management in primary care. Fam Pract. 1996;13(2):133-7.

71. Hoch I, et al. Countrywide computer alerts to community physicians improve potassium testing in patients receiving diuretics. J Am Med Inform Assoc. 2003;10(6):541-6.

72. Kortteisto T, et al. Patient-specific computer-based decision support in primary healthcare-a randomized trial. Implement Sci. 2014;9:15.

73. Litvin CB, et al. Use of an electronic health record clinical decision support tool to improve antibiotic prescribing for acute respiratory infections: the ABX-TRIP study. J Gen Intern Med. 2013;28(6):810-6.

74. Lobach DF, Hammond WE. Computerized decision support based on a clinical practice guideline improves compliance with care standards. Am J Med. 1997;102(1):89-98.

75. Malone DC, Saverno KR. Evaluation of a wireless handheld medication management device in the prevention of drug-drug interactions in a Medicaid population. J Manag Care Pharm. 2012;18(1):33-45.

76. Mayne SL, et al. Effect of decision support on missed opportunities for human papillomavirus vaccination. Am J Prev Med. 2014;47(6):734-44.

77. Nilasena DS, Lincoln MJ. A computer-generated reminder system improves physician compliance with diabetes preventive care guidelines. Proc Annu Symp Comput Appl Med Care. 1995:640-5.

78. Patkar V, et al. Evidence-based guidelines and decision support services: a discussion and evaluation in triple assessment of suspected breast cancer. Br J Cancer. 2006;95(11):1490-6.

79. Piening $\mathrm{S}$, et al. The additional value of an e-mail to inform healthcare professionals of a drug safety issue: a randomized controlled trial in the Netherlands. Drug Saf. 2013;36(9):723-31.

80. Reeve JF, Tenni PC, Peterson GM. An electronic prompt in dispensing software to promote clinical interventions by community pharmacists: a randomized controlled trial. Br J Clin Pharmacol. 2008;65(3):377-85.

81. Ribeiro-Vaz I, et al. Promoting spontaneous adverse drug reaction reporting in hospitals using a hyperlink to the online reporting form: an ecological study in Portugal. Drug Saf. 2012;35(5):387-94.

82. Rocha BH, et al. Clinicians' response to computerized detection of infections. J Am Med Inform Assoc. 2001;8(2):117-25.

83. Ruland CM. Handheld technology to improve patient care: evaluating a support system for preference-based care planning at the bedside. J Am Med Inform Assoc. 2002;9(2):192-201.

84. Schwarz EB, et al. Clinical decision support to promote safe prescribing to women of reproductive age: a cluster-randomized trial. J Gen Intern Med. 2012;27(7):831-8.

85. Sharifi $M$, et al. Enhancing the electronic health record to increase counseling and quit-line referral for parents who smoke. Acad Pediatr. 2014;14(5):478-84.

86. Strayer SM, et al. Improving smoking cessation counseling using a point-ofcare health intervention tool (IT): from the Virginia Practice Support and Research Network (VaPSRN). J Am Board Fam Med. 2013;26(2):116-25.

87. Strom BL, et al. Unintended effects of a computerized physician order entry nearly hard-stop alert to prevent a drug interaction: a randomized controlled trial. Arch Intern Med. 2010;170(17):1578-83.

88. Tang PC, et al. Measuring the effects of reminders for outpatient influenza immunizations at the point of clinical opportunity. J Am Med Inform Assoc. 1999;6(2):115-21.

89. Vagholkar $\mathrm{S}$, et al. Influence of cardiovascular absolute risk assessment on prescribing of antihypertensive and lipid-lowering medications: a cluster randomized controlled trial. Am Heart J. 2014;167(1):28-35.

90. Walker J, et al. Computer reminders for chlamydia screening in general practice: a randomized controlled trial. Sex Transm Dis. 2010;37(7):445-50.

91. Lipsey MW, Wilson DB. Practical meta-analysis, vol. 49. Thousand Oaks: Sage publications; 2001

92. Barnett J, et al. myPace: an integrative health platform for supporting weight loss and maintenance behaviors. IEEE J Biomed Health Inform. 2015; 19(1):109-16. 
93. Bokhour BG, et al. The role of evidence and context for implementing a multimodal intervention to increase HIV testing. Implement Sci. 2015;10:22.

94. Burns $P$, et al. The introduction of electronic medication charts and prescribing in aged care facilities: an evaluation. Australas J Ageing. 2007; 26(3):131-4.

95. Doerr $\mathrm{M}$, et al. Formative evaluation of clinician experience with integrating family history-based clinical decision support into clinical practice. J Pers Med. 2014;4(2):115-36.

96. Dowding $D$, et al. Nurses' use of computerised clinical decision support systems: a case site analysis. J Clin Nurs. 2009;18(8):1159-67.

97. Dryden EM, et al. Provider perspectives on electronic decision supports for obesity prevention. Clin Pediatr (Phila). 2012;51(5):490-7.

98. Guldberg $T L$, et al. Suboptimal quality of type 2 diabetes care discovered through electronic feedback led to increased nurse-GP cooperation. A qualitative study. Prim Care Diabetes. 2010;4(1):33-9.

99. Hains IM, et al. Standardizing care in medical oncology: are web-based systems the answer? Cancer. 2009;115(23):5579-88.

100. Litvin CB, et al. Adoption of a clinical decision support system to promote judicious use of antibiotics for acute respiratory infections in primary care. Int J Med Inform. 2012;81(8):521-6.

101. Maguire R, et al. Nurse's perceptions and experiences of using of a mobilephone-based Advanced Symptom Management System (ASyMSC) to monitor and manage chemotherapy-related toxicity. Eur J Oncol Nurs. 2008; 12(4):380-6.

102. Mandt I, Horn AM, Granas AG. [Communication about prescription interventions between pharmacists and general practitioners]. Tidsskr Nor Laegeforen. 2009;129(18):1846-9.

103. Power $\mathrm{JMH}$, et al. Integration of smartphones into clinical pharmacy practice: an evaluation of the impact on pharmacists' efficiency. Health Policy and Technology. 2014;3(4):296-305.

104. Randell R, Dowding D. Organisational influences on nurses' use of clinical decision support systems. Int J Med Inform. 2010;79(6):412-21.

105. Rousseau N, et al. Practice based, longitudinal, qualitative interview study of computerised evidence based guidelines in primary care. BMJ. 2003; 326(7384):314

106. Saleem JJ, et al. Exploring barriers and facilitators to the use of computerized clinical reminders. J Am Med Inform Assoc. 2005;12(4):438-47.

107. Vishwanath $A$, et al. Patterns and changes in prescriber attitudes toward PDA prescription-assistive technology. Int J Med Inform. 2009;78(5):330-9.

108. Weir $\mathrm{C}$, et al. The role of information technology in translating educational interventions into practice: an analysis using the PRECEDE/PROCEED model. J Am Med Inform Assoc. 2011;18(6):827-34.

109. Zhu X, Cimino JJ. Clinicians' evaluation of computer-assisted medication summarization of electronic medical records. Comput Biol Med. 2015:59:221-31.

Ready to submit your research? Choose BMC and benefit from:

- fast, convenient online submission

- thorough peer review by experienced researchers in your field

- rapid publication on acceptance

- support for research data, including large and complex data types

- gold Open Access which fosters wider collaboration and increased citations

- maximum visibility for your research: over $100 \mathrm{M}$ website views per year

At $\mathrm{BMC}$, research is always in progress.

Learn more biomedcentral.com/submissions 